\title{
Enabling the Investigation of Structure Vulnerabilities to Wind- Driven Firebrand Showers in Wildland-Urban Interface (WUI) Fires
}

\author{
SAMUEL L. MANZELLO \\ Fire Research Division, Engineering Laboratory \\ National Institute of Standards and Technology (NIST) \\ 100 Bureau Drive, Gaithersburg, MD 20899-8662 USA
}

\begin{abstract}
Wind-driven firebrand showers are a major cause of structural ignition in Wildland-Urban Interface (WUI) fires. Past firebrand investigations have not been able to quantify the vulnerabilities of structures to ignition from firebrand showers, as it is difficult to develop a measurement method to replicate wind-driven firebrand attack on structures that occur in actual WUI fires. To address this problem, research has been undertaken in an intricate area involving the quantification of structure vulnerabilities to wind-driven firebrand showers. This type of firebrand research has never been possible prior to the development of the NIST Firebrand Generator, also referred to as the NIST Dragon. Due the complexity of the WUI fire problem, great strides must be made to recruit the next generation of researchers to fire safety science from diverse backgrounds. This paper closes with a discussion of ongoing workshop activities intended to achieve this, as well as some challenges for future WUI fire research.
\end{abstract}

KEYWORDS: wildland-urban interface fires; firebrands; ignition

\section{WILDLAND URBAN INTERFACE (WUI) FIRES: AN EMERGING AREA IN FIRE SAFETY SCIENCE}

Wildfires that spread into communities, referred to as Wildland-Urban Interface (WUI) fires, have destroyed communities throughout the world. The 2007 Southern California Fire forced 300,000 people to evacuate, destroyed over one thousand structures, and resulted in $\$ 1 \mathrm{~B}$ paid by insurers [1]. In Europe, the 2007 fires in Greece destroyed several hundred structures, and resulted in the deaths of more than 70 people. In Australia, the 2009 fires in Victoria caused the death of 173 people and destroyed more than one thousand structures [2].

WUI fires continue to burn in the USA, and are rapidly getting worse, with attendant increased economic costs [3]. Some recent examples include in the Bastrop Complex Fire in Texas in 2011, the Waldo Canyon Fire in Colorado in 2012, and fires in Arizona, Colorado, and California in 2013. Tragically, 19 firefighters lost their lives in 2013 battling WUI fires in Yarnell, Arizona. This was the largest single loss of life for firefighters since the September 11, 2001 terrorist attacks on the World Trade Center in New York.

The WUI fire problem can be viewed as a structure ignition problem [4]. Surprisingly, little effort has been spent on understanding the processes of structure ignition in these fires. Scientifically-based building codes and standards are needed to guide construction of new structures in areas prone to WUI fires in order to reduce the risk of structural ignition. Scientifically-based retrofitting strategies are required for homes already located in areas prone to such fires.

Historically, fire safety science research has spent a great deal of effort to understand fire dynamics within buildings. Research into WUI fires, and how to potentially mitigate the loss of structures in such fires, is far behind other areas of fire safety science research. This is due to the fact that fire spread in the WUI is incredibly complex, involving the interaction of topography, weather, vegetation, and structures [5].

When vegetation and structures burn in WUI fires, pieces of burning material, known as firebrands, are generated, become lofted, and are carried by the wind. This results in showers of wind-driven firebrands. Post-fire studies indicate that firebrand showers are a significant factor in the spread of WUI fires [6-10]. Interestingly, post-fire damage studies have suggested for some time that firebrands are a significant cause 
of structure ignition in WUI fires, yet for decades, firebrand studies have focused on understanding spotting distance [11-19; there are many more transport studies not referenced in the interest of space]. As discussed in this paper, firebrand generation data from vegetation, structures, and actual WUI fires is sparse [20-29], and most of these generation studies were actually conducted by NIST. The same may be said regarding firebrand ignition studies [30-36].

Firebrand investigations have not been able to quantify the vulnerabilities of structures to ignition from firebrand showers, as it is difficult to develop a measurement method to replicate wind-driven firebrand bombardment on structures that occur in actual WUI fire events. To address this problem, research has been undertaken in an intricate area involving the quantification of structure vulnerabilities to wind drivenfirebrand showers. This type of firebrand research has never been possible prior to the development of the Firebrand Generator (Dragon).

Due the complexity of the WUI problem, great strides must be made to recruit the 'next generation' of researchers to fire safety science from diverse backgrounds. This paper provides a discussion of ongoing activities intended to achieve this, as the WUI problem continues to increase, the future of fire safety science research is more important than ever. A series of difficult challenges for future WUI research are outlined as well.

\section{DEVELOPMENT OF NEW EXPERIMENTAL TECHNOLOGY: NIST FIREBRAND GENERATOR (AKA NIST DRAGON)}

The NIST Firebrand Generator (NIST Dragon) has been constructed to generate controlled, repeatable firebrand showers commensurate to those measured from burning conifers, and a real WUI fire (see Fig. 1). The purpose of the NIST Dragon is to simulate wind-driven firebrand showers observed in long-range spotting. As a result, glowing firebrands were the initial emphasis. Yet, due to careful design of the NIST Dragon, it is also possible to generate showers of flaming firebrands. Since wind is an important component of WUI fire spread, NIST established collaboration with the Building Research Institute (BRI) in Japan. BRI's Fire Research Wind Tunnel Facility (FRWTF), constructed in the late 1990s, is one of the first wind tunnel facilities in the world designed specifically with fire experiments in mind. The FRWTF provides wind speeds up to $10 \mathrm{~m} / \mathrm{s}$, with a cross-section $4.0 \mathrm{~m}$ (high) by $5.0 \mathrm{~m}$ (wide), and test section length of $15.0 \mathrm{~m}$.

A very important characteristic of the NIST Dragon is that the firebrand size and mass produced using the device can be tailored to those measured from full-scale tree burns [26-27], and actual WUI fires [20], which are in stark contrast with the size of firebrands referenced in existing test standards and wildfire protection building construction recommendations. In collaboration with the California Department of Forestry and Fire Protection (CALFIRE), NIST quantified firebrand distributions from a real WUI fire (2007 Angora Fire) for the first time [20]. Specifically, digital image analyses of burn patterns from materials exposed to the Angora Fire were conducted to determine firebrand size distributions. The firebrand size distributions reported were compared to firebrand size distributions from experimental firebrand generation using the NIST Dragon, as well as historical firebrand field studies [23-24]. The most salient result reported in [20] was the documentation of the consistently small size of firebrands $\left(<0.5 \mathrm{~cm}^{2}\right)$ and the close correlation of these results with the sizes of experimentally generated firebrands from the NIST Dragon. The Texas Forest Service has used this methodology to collect firebrand size distributions from the recent Texas Bastrop Complex fires in 2011, as well, and reported similar findings to the 2007 Angora fire; significant numbers of very small firebrands were produced [21]. More of this type of information is clearly needed from actual WUI fires, and is described below as an important challenge for future WUI fire research.

Experimental investigations have been conducted using the NIST Dragon installed in BRI's FRWTF to expose roofing assemblies, building vents, siding treatments, walls fitted with eaves, and glazing assemblies to wind-driven firebrand showers [38-42]. In addition, the dangers of firebrand accumulation in front of structures have been quantified for the first time. The interested reader is referred to [43-44], as two recent reviews have been completed, and describe the highlights of this research conducted over the 
past several years. Some key findings from these recent reviews are provided here, as well as new results not yet published in the archival literature. For completeness, a typical experiment is shown in Fig. 2.

The 2007 California Building Code of Regulations, Title 24, Part 2, Chapter 7A recommended that a metal mesh of $6 \mathrm{~mm}$ be placed behind building vents to prevent firebrand entry into structures [43-44]. The mesh size was not based on any scientific testing since no test methods were available at that time. The penetration of firebrands into building vents was studied for the first time using the NIST Dragon at BRI's FRWTF. These results showed that firebrands were not quenched by the presence of the mesh but would continue to burn on the mesh until they were small enough to be transported through the mesh opening. For the $6 \mathrm{~mm}$ mesh, a majority of the firebrands simply flew through the mesh, resulting in more rapid ignition of flammable materials behind the mesh than that observed for the smaller mesh sizes of $3 \mathrm{~mm}$ and $1.5 \mathrm{~mm}$. During the 2010 triennial code change cycle in California, no standard test methods were available to evaluate and compare firebrand-resistant vent technologies. NIST worked with CALFIRE as part of a task force in order to reduce mesh size used to cover building vent openings to lessen the potential hazard of firebrand entry into structures. Requirements for reduced mesh sizes were formally adopted into the 2010 California Code of Regulations, Title 24, Part 2, Chapter 7A, and were effective January 2011 [43-44].

While standard test methods are in place to test ignition of roofing decks to firebrands by placing a burning wood crib on top of a section of a roof assembly under an air flow, the dynamic process of multiple firebrands landing under ceramic tiles/gaps as a function of time is not taken into account [39]. Post-fire studies have identified a building ignition mechanism where small firebrands penetrate under noncombustible tile roof coverings [20]. Experiments conducted using the NIST Dragon have provided experimental confirmation of this ignition mechanism for ceramic tile roofing [39].

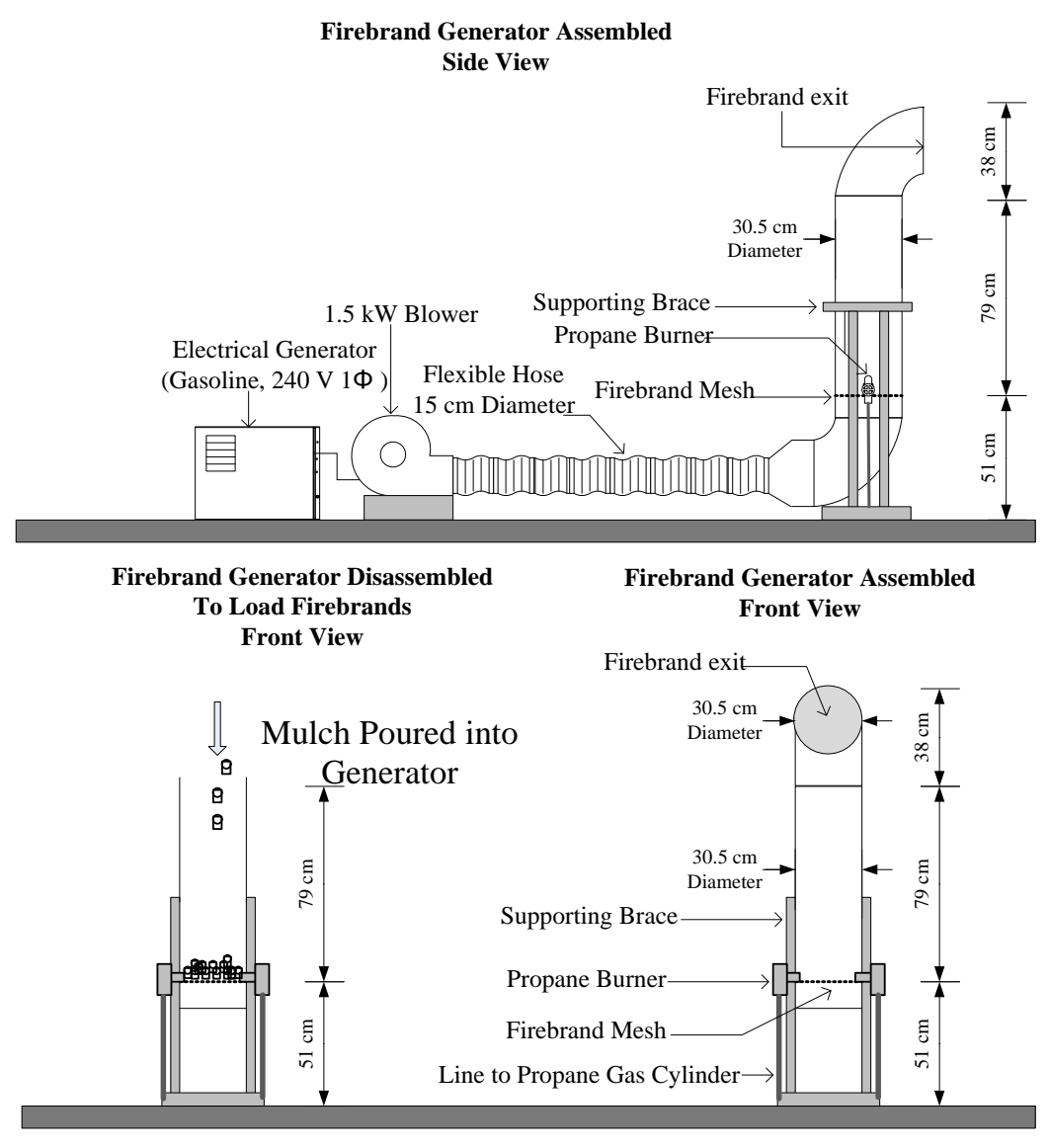

Figure 1 Schematic of the NIST Firebrand Generator (NIST Dragon). 
Recently, concrete tile roofing assemblies (flat and profiled tile) as well as terracotta tile roofing assemblies (flat and profiled tile) commonly used in the USA, Australia, and elsewhere were exposed to wind-driven firebrand showers [42]. The purpose of these scoping experiments was to determine if firebrands were able to penetrate the tile assemblies and melt the underlying sarking material. No decking was included in the roof support structure as these experiments were intended to replicate Australian construction details. The results, however, are relevant to US construction since the same concrete (flat and profiled) and terracotta (flat and profiled) tiles are used in both countries. Underlayment or sarking, in the form of a layer of aluminium foil laminate bonded with a fire retardant adhesive to a polymer fabric, was placed under the tile battens. The results showed that firebrands penetrated the tile gaps and subsequently melted the sarking material for both types of concrete tile roofing assemblies (flat and profiled tile) and the profiled tile terracotta roofing assembly when exposed to wind-driven firebrand showers. The flat tile terracotta roofing assembly performed best probably due to its interlocking design. For these tiles, the firebrands were observed to become trapped within the interlocking sections of the tiles and as a result, the firebrands were not transported past the tiles towards the sarking material. Based on the findings of these experiments, a potential cost-effective mitigation strategy might be to use a continuous underlayment of firebrand-resistant sarking [42].

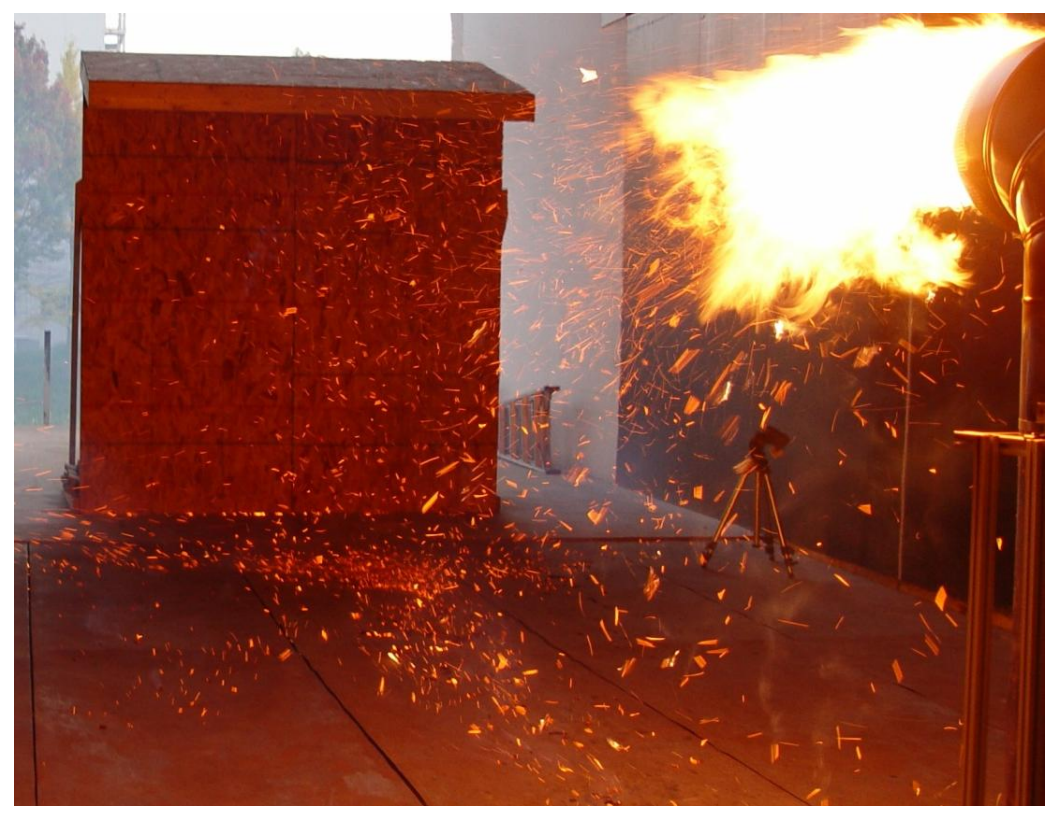

Figure 2 A typical experiment involving the NIST Dragon at BRI's FRWTF. In this image, a wall assembly $(244 \mathrm{~cm}$ by $244 \mathrm{~cm})$ fitted with open eave $(61 \mathrm{~cm}$ overhang) is exposed to wind-drive firebrand showers at $9 \mathrm{~m} / \mathrm{s}$.

The NIST Dragon technology has now been duplicated by other research laboratories. Specifically, the Insurance Institute for Business and Home Safety (IBHS) has used the NIST Dragon concept to generate firebrand showers in their full-scale wind tunnel facility [45]. Most recently, Underwriters Laboratories (UL) has also constructed the NIST Dragon and is using it their research laboratory.

\section{CONTINUOUS WIND-DRIVEN FIREBRAND SHOWERS}

Bench scale test methods efficiently evaluate firebrand resistant building elements, and may serve as the basis for new standard testing methodologies. To this end, the NIST Dragon's LAIR (Lofting and Ignition Research) facility simulates wind driven firebrand showers at bench-scale [40]. This facility consists of a bench scale Firebrand Generator (known as the NIST Baby Dragon) coupled to a bench-scale wind tunnel. While the NIST Dragon's LAIR facility and the full-scale NIST Dragon coupled to BRI's FRWTF (described above) have been used to expose building elements to firebrand showers, the duration of exposure using the existing apparatus is limited. To develop test methods needed to evaluate different building materials resistance to firebrand showers requires the capability to generate firebrand showers of 
varying duration. To determine if it was feasible to develop a continuous feed Firebrand Generator, it was decided to first improve the bench-scale device (Baby Dragon). Accordingly, the NIST bench scale continuous feed Firebrand Generator (the NIST continuous feed Baby Dragon) was developed. The unique features of the NIST continuous feed Baby Dragon, over the present NIST Baby Dragon, are the ability to produce a constant firebrand shower in order to expose building materials to continual firebrand bombardment. The performance of this device has been characterized, and this was presented at the last IAFSS symposium [46]. The Dragon's LAIR facility has now been upgraded to include the NIST continuous feed Baby Dragon (see Fig. 3). The interested reader is referred elsewhere for a very detailed description of the new and improved Dragon's LAIR facility [47]. The NIST continuous feed Baby Dragon has been cloned by the University of Coimbra - Institute for Interdisciplinary Research, Europe's largest institute focused on WUI fires, as well as the National Research Institute of Fire and Disaster (NRIFD) in Japan, a part of the Japanese government.

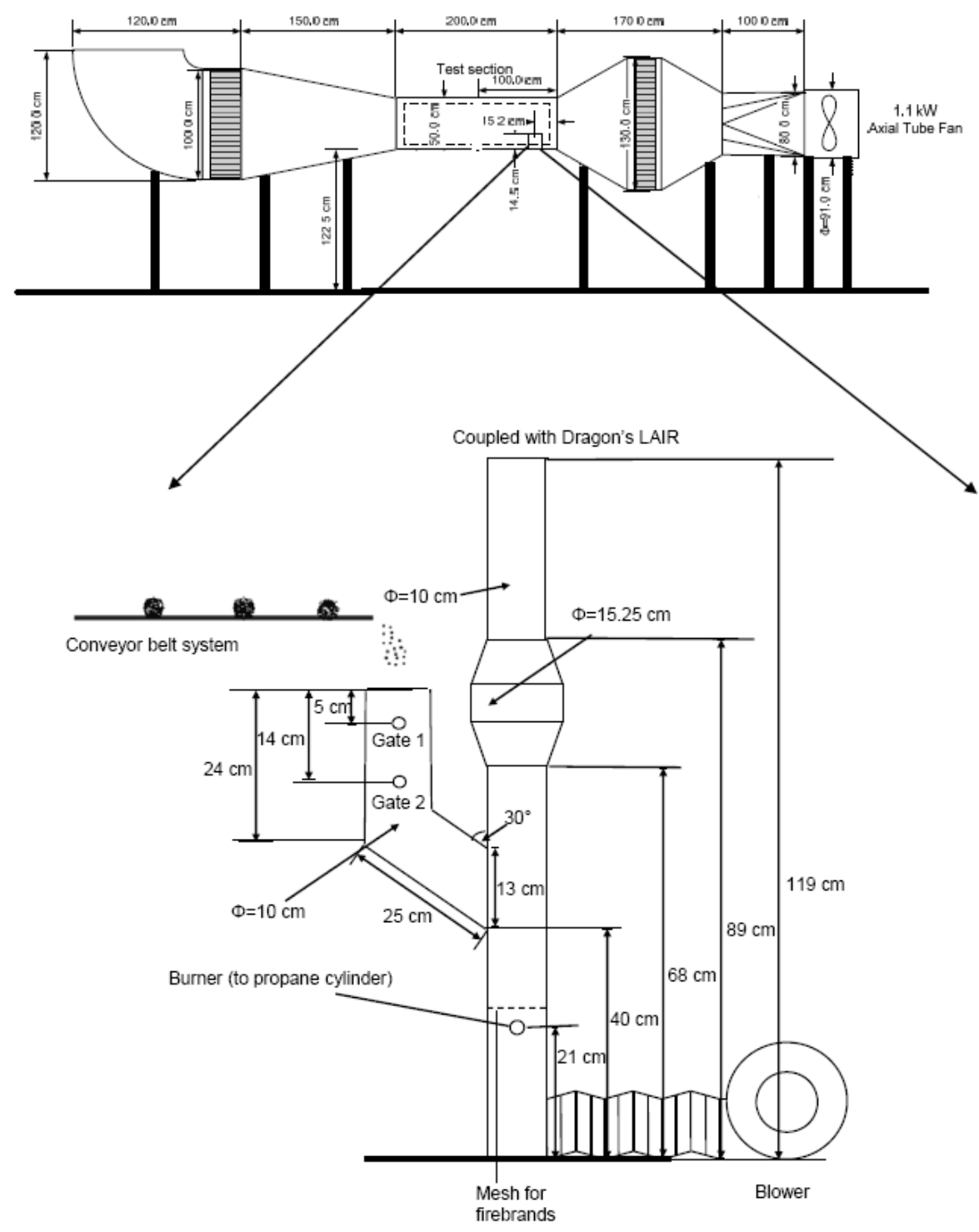

Figure 3 Schematic of NIST Dragon's LAIR (Lofting and Ignition Research) Facility. 
Efforts were undertaken to scale this device up and construct a full-scale continuous feed Firebrand Generator for use in BRI's FRWTF. The capability of this new experimental device to generate continuous wind-driven firebrand showers, and direct them towards decking assemblies, is presented in these IAFSS proceedings [48]. As a result, only a brief description of this apparatus is provided below, and the interested reader is referred elsewhere [44, 48].
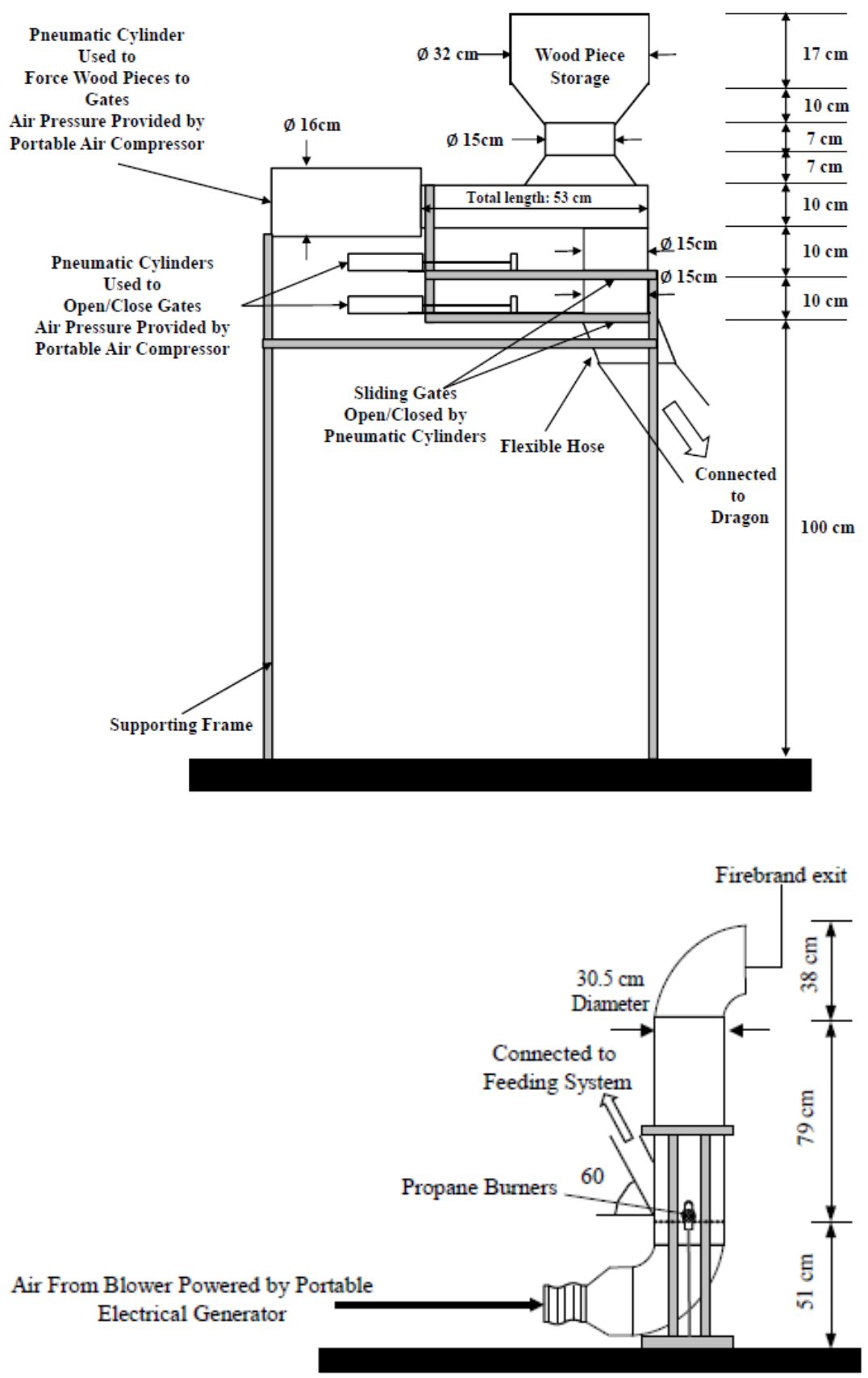

Figure 4 Detailed schematic of the feeding system for the full-scale continuous feed firebrand Firebrand Generator (top); side view of the main body (or Dragon) and the location where the feeding system provided wood pieces into the device is shown. 
This version of the device is modified from the NIST Dragon [38-42], and consisted of two parts: the main body and continuous feeding component (see Fig. 4). The feeding part was connected to the main body and was equipped with two gates to prevent fire spread (described in more detail below). A major challenge when constructing this device was designing a completely contained feeding system shielded from the wind tunnel flow. The feeding system consisted of a pneumatic cylinder coupled to a cylindrical container where wood pieces were stored. The pneumatic cylinder was contained inside a metal sleeve. Inside the metal sleeve, the sliding rod of the pneumatic cylinder was connected to a plate that allowed the volume of wood contained within the sleeve to be varied. This volume was set precisely to allow a specific mass of firebrands to fall into this volume. When the air pressure was applied, the sliding rod of the pneumatic cylinder moved forward, forcing the wood pieces that have fallen by gravity within the volume of the metal sleeve to the first gate, where they are then dropped into second gate that leads to the Dragon where they are ignited (see Fig. 4). The mass flux of generated firebrands may be adjusted by varying the feeding rate of wood pieces into the device; all experiments so far have utilized a wood feeding rate of $800 \mathrm{~g} / \mathrm{min}$, which resulted in a mass flux of firebrands of $17.1 \mathrm{~g} / \mathrm{m}^{2} \mathrm{~s}$.

As in prior experiments using the NIST Dragon, the new experimental device was installed inside BRI's FRWTF. So far, experimental investigations have been conducted to determine the vulnerabilities of decking assemblies, mulch beds of various moisture contents, and fencing assemblies to continuous winddriven firebrand showers. Since the decking assembly results are presented in these IAFSS proceedings, as well as the specific justification to study decks in the first place, these results are not presented here [48]. Post-fire studies conducted by NIST on the Waldo Canyon Fire in Colorado that occurred in 2012, determined that wood fences are believed to be vulnerable to ignition from firebrand showers in WUI fires but, again, there has never been any experimental verification of this ignition mechanism. As a result, a series of experiments were conducted to expose Cedar and Redwood fencing assemblies to wind-driven firebrand showers. A discussion of the mulch bed experiments follows below.

As indicated, developing the scientific-basis necessary to support test methods for firebrand resistant building elements is a key component required to reduce the WUI fire problem, as it is a structure ignition issue. In the WUI, buildings are often surrounded by vegetation that, when ignited, can produce intense, localized firebrand showers, and provide direct flame contact onto building elements, leading to ignition of buildings. The creation of defensible space around structures is a common mitigation strategy, yet in many areas the requirement for the creation of defensible space is either not popular due to resistance to modify the natural environment and landscaping around structures, or not practical due to limited lot size. Of particular concern are landscape mulches located adjacent to buildings. While there have been some studies of mulch ignition in the literature, none of these studies have investigated the ignition of mulch installed in realistic building configurations exposed to wind-driven firebrand showers; conditions seen in real WUI fires.

Figure 5 displays a typical experiment to expose mulch beds to continuous wind-driven firebrand showers. In this image, the wind tunnel speed was $6 \mathrm{~m} / \mathrm{s}$ and the mulch bed moisture content (MC) was $11 \%$. In this experiment, the firebrand mass flux directed at the mulch bed/re-entrant corner assembly was fixed. The mulch bed MC was defined as:

$$
\text { Moisture Content }=\frac{M_{w e t}-M_{d r y}}{M_{d r y}} * 100
$$

where $M_{w e t}$ and $M_{d r y}$ represent the mulch mass before and after oven drying, respectively. For the mulch beds, smoldering ignition (SI) was first observed, and SI was observed to transition to flaming ignition (FI). The present of SI was indicted by intense smoke generation and glowing combustion in the mulch bed. The time for sustained FI to be reached was determined. The time was defined as the time sustained FI was observed within the mulch bed less the time the first firebrand landed on the mulch bed surface. For fixed wind tunnel speed (set to either $6 \mathrm{~m} / \mathrm{s}$ or $8 \mathrm{~m} / \mathrm{s}$ ), and fixed firebrand mas flux generated from the Continuous Feed Dragon, experiments were conducted at three different MC levels. Oven dried conditions were intended to represent a worst-case scenario. Mulch bed MC up to $25 \%$ represented intermediate fuel moisture levels, and were compared to results from available literature studies. Higher MC levels represented very wet mulch to determine if continuous firebrand showers could produce ignition under such 'wet' conditions. The rationale behind such tests was based on using water as a wetting agent to 
potentially mitigate ignition; so called fuel pre-wetting. While full details of these results are beyond the scope of this paper, it is rather clear that continuous-wind driven firebrand showers are capable of rapidly igniting mulch beds (see Fig. 5).

\section{FIREBRAND GENERATION FROM BURNING STRUCTURES}

It is believed that in WUI fires, the structures themselves may be a large source of firebrands, in addition to the vegetation. Yet, due to lack of quantitative information available on production of firebrands from structures, it cannot be determined if firebrand production from structures is a significant source of firebrands in WUI fires. Determining firebrand generation from burning structures will also allow the Firebrand Generator to generate different firebrand size/mass distributions.
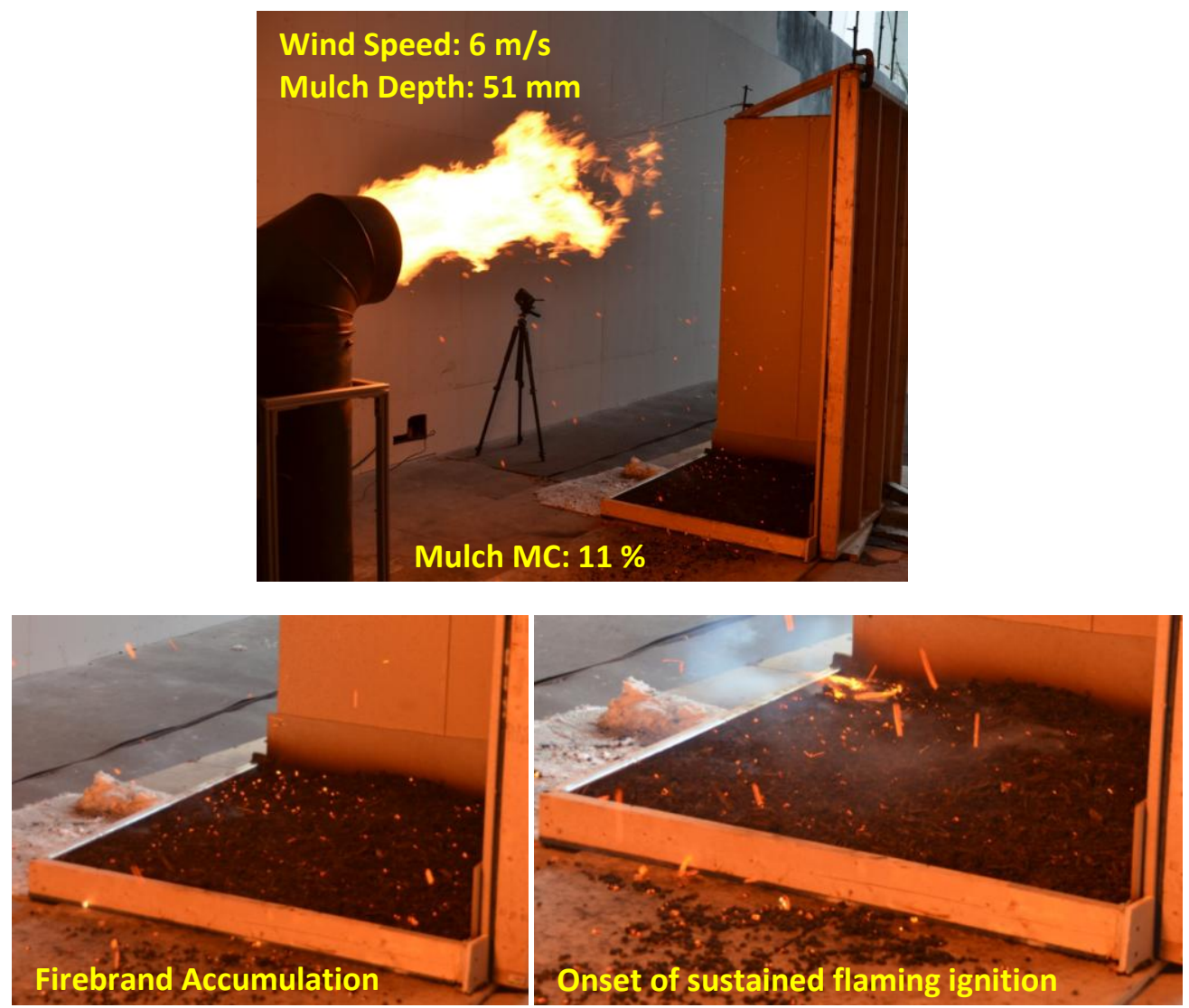

Figure 5 Image of $1.2 \mathrm{~m}$ by $1.2 \mathrm{~m}$ by $51 \mathrm{~mm}$ (depth) shredded hardwood mulch bed at $11 \%$ MC exposed to continuous wind-driven firebrand showers. The re-entrant corner, with dimensions of $1.2 \mathrm{~m}$ by $1.2 \mathrm{~m}$ by $2.44 \mathrm{~m}$ high, was lined with gypsum board to investigate the ignition of the mulch bed itself; the ability of the mulch bed to ignite the wall assembly was not considered. Sustained FI was observed.

To this end, an experimental database is being generated from firebrand generation from structures. In the first phase of this work, an experiment was conducted to collect firebrands from a two story house located in Dixon, CA [28]. Debris piles were used to ignite the structure and it took approximately two hours after ignition for complete burn down. A large amount of water was poured onto the structure several times to control the fire since the house was located in a populated section of downtown Dixon. Firebrands were collected with a series of water pans placed near $(4 \mathrm{~m})$ the structure and on the road about $18 \mathrm{~m}$ downwind of the structure. 


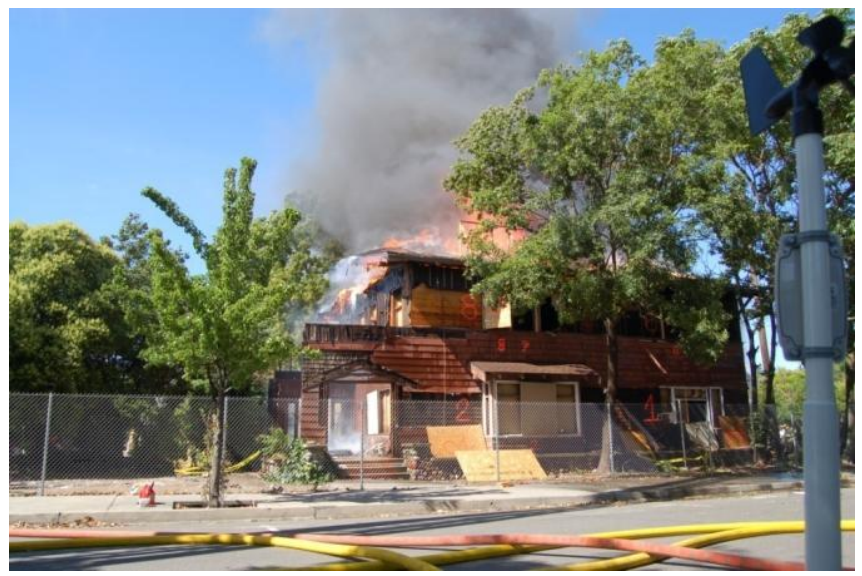

Figure 6 Structure burning (30 min after ignition) for firebrand collection [28].

Subsequently, firebrand production from real-scale building components under well-controlled laboratory conditions was determined using BRI's FRWTF [29]. Specifically, wall and re-entrant corner assemblies were ignited and during the combustion process, firebrands were collected to determine the size/mass distribution generated from such real-scale building components under varying wind speed. The purpose of those experiments was to determine if useful information regarding firebrand generation can be obtained from simple components tests. Components experiments are far simpler than the full-scale structure experiments, described above. It was observed that similar mass distributions of firebrands were observed from components to the available full-scale structure tests in the literature [29]. An image of a re-entrant corner ignited for firebrand collected, constructed from simplified building materials (wood stud, and oriented strand board - OSB; no siding applied), is shown in Figure 7. While structures in WUI communities are made from various materials, the components used for this experiment were simplified, in order to demonstrate the feasibility of such testing and attempt to determine rate limiting materials for firebrand production. It is important to perform more experiments which will more closely replicate real construction under well-controlled conditions. As a result, experiments have recently been conducted by applying cedar siding to individual building components, and the interested reader may find some information about those results elsewhere [49].

\section{RECRUITING THE NEXT GENERATION OF RESERCHERS TO FIRE SAFETY SCIENCE}

With growing pressures on research budgets worldwide, the field of fire safety science is in need of stronger research ties across the 'next generation' of researchers to share and pool resources to investigate important emerging topics of great need to certain countries. It is clear that WUI fires are an important, emerging research topic in fire safety engineering. Another prominent example of large outdoor fires that present risk to the built environment is urban fires, common in Japan. While there are substantial phenomenological similarities between urban and WUI fires, research in Japan and in the USA has been conducted in each country independently, with little chance of constructive research collaboration. A kickoff workshop was held at NIST in June, 2011 to bring these research communities together. Contributed papers from this workshop appeared in a special issue of Fire Safety Journal in 2012 [50].

NIST entered into a partnership with the Japan Association for Fire Science and Engineering (JAFSE) to hold two more workshops. The first of these workshops, known as "Operation Tomodachi - Fire Research" was held in Tokyo, Japan on July, 2012 [51]. Tomodachi means friendship in Japanese. The objective was to: (1) develop scientific knowledge and translate it to building codes and standards that will be of use to both countries to reduce the devastation caused by unwanted fires, (2) provide a forum for next generation researchers to present their work in order to develop new research collaborations, (3) and allow USA participants a chance to visit excellent large-scale research facilities available in Japan that are of use to the research topics of this workshop. It is desired that this activity will motivate the next generation of researchers to explore and develop research collaborations related to emerging areas of fire safety science. 
It is hopeful that new and exciting activities specific to other countries may come out of this type of event. Planning is now underway for the follow-on workshop to be held at NIST in 2015.

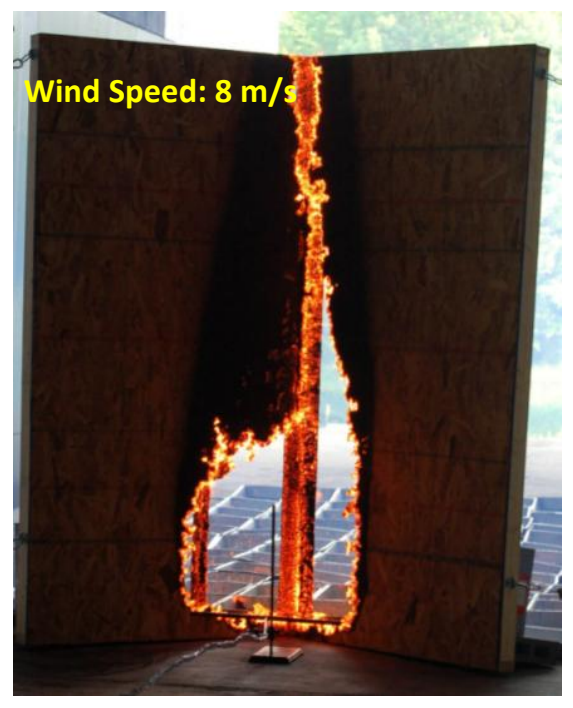

Figure 7 Re-entrant corner wall assembly burning under an $8 \mathrm{~m} / \mathrm{s}$ wind field. Further details of these experiments are provided in [29].

The journal Fire Technology is also working to bring attention to the WUI fire problem. A special issue, the first devoted to WUI fires in the fire safety science area, has been published [5]. In this issue, papers are published from all over the world, and it highlights the need for more WUI research to the fire safety science community.

\section{FUTURE DIRECTIONS OF WUI RESEARCH}

There remains a great deal of work to do to further quantify structure vulnerabilities to wind-driven firebrand showers. The foundation laid in this paper will inform test method development for a new generation of effective WUI building codes and standards, since the best way forward to address the WUI problem is hardening of structures [52]. Future work should consider generating data to inform the development of a NIST WUI Hazard Scale [53], which will be used to establish a basis for the levels of hardening needed for buildings and communities to protect against exposure from WUI fires. Specific research needs include:

- fundamental understanding of firebrand ignition mechanisms

- characterize firebrand size/mass distributions from a wide variety of actual fire scenes

- $\quad$ evaluate performance of technologies intended to mitigate firebrand ignition of structures

- measure resistance to ignition of additional building components to firebrand showers

- firebrand exposure to coupled building components (e.g. deck connected to combustible wall)

- couple firebrand generator with radiant panels to study combined radiation/firebrand influences

- consider higher wind speeds as all experiments to date have been conducted up to wind speeds of $10 \mathrm{~m} / \mathrm{s}$, and WUI fires have occurred under wind speeds in excess of $20 \mathrm{~m} / \mathrm{s}$.

Many organizations need to contribute to satisfactorily address this challenging problem. More data is needed for firebrand size/mass distributions from various types of vegetation, structures, and actual WUI fires. The experiments conducted by NIST for firebrand generation from burning trees are the only known studies [26-27]. As more data becomes available, the Firebrand Generator can produce different firebrand distributions representative of various realistic firebrand distributions. As indicated above, the methodologies developed by NIST, in collaboration with CALFIRE, to collect firebrand size information from actual WUI fires, have been used by the Texas Forest Service. Yet, the Angora fire data set, and the 
Texas Fire data set, remain the only know detailed data on firebrand size distributions from actual WUI fires.

Most of the building components exposed to wind-driven firebrand showers that have been described in this paper were based on post-fire studies conducted by NIST and elsewhere. More post-fire data collection of actual WUI events is required to understand the dynamics of WUI fire spread, and what types of building elements may be vulnerable to wind-driven firebrand showers. The interested reader is referred elsewhere to some past post-fire WUI data collection studies [6-10].

When WUI fires spread into communities, the combined influence of firebrand showers, and radiative heat flux, is believed to contribute to ignition of structures. Radiative heat flux is generated as vegetation and other structures burn in WUI fires within communities. Plans are underway to construct a new experimental apparatus that will afford the investigation of these combined effects, and install it inside a full-scale wind tunnel facility. This new capability directly feeds into the NIST developed WUI Hazard Scale [53], since it will be possible to expose any type of building assembly to different levels of combined firebrand and radiative flux, thus enabling the ability to design structures to various exposures.

IBHS has used the NIST Dragon concept to generate firebrand showers in their new (opened in 2011) fullscale wind tunnel facility that is capable of wind speeds higher than $10 \mathrm{~m} / \mathrm{s}$ [45]. At present, they have no capability to conduct continuous firebrand showers since they have implemented an array of firebrand generators based on the original NIST Dragon described in this paper. Full-scale experiments in this facility would benefit from continuous firebrand showers, as discussed earlier in this paper.

\section{SUMMARY}

In this paper, a summary has been provided on an extended research effort to quantify structure vulnerabilities to wind-driven firebrand showers. These results have laid the foundation for this important research direction. The author hopes that a next generation researcher will be inspired to work in WUI fire research, and fire safety science in general, after reading this paper. This field provides immense challenge.

\section{ACKNOWLEDGMENTS}

Dr. Sayaka Suzuki, with the National Research Institute of Fire and Disaster (NRIFD) conducted many of these experiments with SLM; this work is not possible without her. Dr. Anthony Hamins, Mr. Nelson Bryner, Dr. William Grosshandler (ret), Dr. Shyam Sunder, and Dr. Jiann. Yang, all of the Engineering Laboratory (EL) at NIST, motivated the author to strive for more in his research endeavors at NIST. Mr. Alexander Maranghides, of EL-NIST has been greatly devoted to the WUI problem, and his efforts are appreciated. Dr. Yoshihiko Hayashi, and Dr. Ichiro Hagiwara, both of BRI (Japan), are appreciated for the strong BRI/NIST partnership that helped make this work possible. SLM also acknowledge the many contributions from Mr. Edward Hnetkovsky, Mr. John Shields, Mr. Laurean DeLauter, Mr. Tony Chakalis, Mrs. Doris Rinehart, and Dr. Matthew Bundy, all of EL- NIST. The Science and Technology Directorate of the U.S. Department of Homeland Security sponsored the production of this material under Interagency Agreement IAA HSHQDC-11-X-00565 with the National Institute of Standards and Technology (NIST).

\section{REFERNCES}

[1] 2007 Annual Report of the Insurance Commissioner, California Department of Insurance.

[2] 2009 Victorian Bushfires Royal Commission, Final Summary Report, July 2010.

[3] Gorte, R., The Rising Costs of Widlfire Protection, Headwaters Economics, 19 pages, June, 2013.

[4] Mell, W.E., Manzello, S.L., Maranghides, A., Butry, D., and Rehm, R.G., (2010) The Wildland-Urban Interface Fire Problem - Current Approaches and Research Needs, International Journal of Wildland Fire, 19: 238-251, http://dx.doi.org/10.1071/WF07131 
[5] Manzello, S.L., (2014) Special Issue on WUI Fires (Guest Editor), Fire Technology 50:7-8, http://dx.doi.org/10.1007/s10694-012-0319-0.

[6] Barrow, G.J. (1945) A Survey of Houses Affected in the Beaumaris Fire, January 14, 1944. Journal of the Council for Scientific and Industrial Research [now CSIRO] 18: 27-37,

[7] Abt R., Kelly D., Kuypers M., (1987) The Florida Palm Coast Fire: An Analysis of Fire Incidence and Residence Characteristics, Fire Technology, 23: 186-197, http://dx.doi.org/10.1007/BF01036938

[8] Foote EID; Structure survival on the 1990 Santa Barbara "Paint" fire: A retrospective study of urbanwildland interface fire hazard mitigation factors, MS thesis, University of California at Berkeley, p. 129; 1994

[9] Gordon D.A., Structure Survival in the Urban/Wildland Interface: A Logistic Regression Analysis of the Oakland/Berkeley Tunnel Fire, MS thesis, University of California at Berkeley, 2000, 447 pp.

[10] Maranghides, A., Mell, W.E., (2011) A Case Study of a Community Affected by the Witch and Guejito Fires, Fire Technology, 47: 379-420, http://dx.doi.org/10.1007/s10694-010-0164-y

[11] Albini, F., (1983) Transport of Firebrands by Line Thermals, Combustion Science and Technology 32: 277-288, http://dx.doi.org/10.1080/00102208308923662

[12] Muraszew, A., Fedele, J.F., Statistical Model for Spot Fire Spread, The Aerospace Corporation Report No. ATR-77758801, Los Angeles, CA, 1976.

[13] Tarifa, C.S., del Notario, P.P., Moreno, F.G. (1965) On the Flight Paths and Lifetimes of Burning Particles of Wood, Proceedings of the Combustion Institute, 10:1021-1037, http://dx.doi.org/10.1016/S0082-0784(65)80244-2.

[14] Anthenian, R., Tse, S.D., Fernandez-Pello, A.C. (2006) On the Trajectories of Embers Initially Elevated or Lofted by Small Scale Ground Fire Plumes in High Winds, Fire Safety Journal 41:349-363, http://dx.doi.org/10.1016/j.firesaf.2006.01.005.

[15] Woycheese, J.P., Brand Lofting and Propagation for Large-Scale Fires, Ph.D. Thesis, University of California, Berkeley, 2000.

[16] Himoto, K., Tanaka, T., (2005) Transport of Disk-Shaped Firebrands in a Turbulent Boundary Layer, in: D. Gottuk and B. Lattimer (Eds.) Fire Safety Science- Proceedings of the Eighth International Symposium, IAFSS, 8:433-444, http://dx.doi.org/10.3801/IAFSS.FSS.8-433.

[17] Knight, I.K., (2007) The Design and Construction of a Vertical Wind Tunnel for the Study of Untethered Firebrands in Flight, Fire Technology 37:87-100, http://dx.doi.org/10.1023/A:1011605719943.

[18] Wang, H.H., (2011) Analysis of Downwind Distribution of Firebrands Sourced from a Wildland fire, Fire Technology, 47:321-340, http://dx.doi.org/10.1007/s10694-009-0134-4.

[19] Koo, E., Pagni, P.J., Weise, D.R., Woycheese, J.P., (2010) Firebrands and Spotting Ignitions in LargeScale Fires, International Journal of Wildland Fire 19: 818-843. http://dx.doi.org/10.1071/WF07119.

[20] Manzello, S.L., and Foote, E.I.D., (2014) Characterizing Firebrand Exposure from Wildland-Urban Interface (WUI) Fires: Results from the 2007 Angora Fire, Fire Technology 50:105-124. http://dx.doi.org/10.1007/s10694-012-02954.

[21] Rissel, S., and Ridenour, K., (2013) Ember Production During the Bastrop Complex Fire, Fire Management Today, 72: 7-13. 
[22] Waterman, T.E., Experimental Study of Firebrand Generation, IIT Research Institute, Project J6130, Chicago, IL, 1969.

[23] Vodvarka, F.J., Firebrand field studies -Final report, IIT Research Institute, Chicago, IL, 1969.

[24] Vodvarka, F.J., Urban Burns-Full-scale field studies -Final report, IIT Research Institute, Chicago, IL, 1970.

[25] Yoshioka, H., Hayashi, Y., Masuda, H., Noguchi, T., (2004) Fire Science and Technology, 23 :142150.

[26] Manzello, S.L., A. Maranghides, A., Mell, W. (2007) Firebrand Generation from Burning Vegetation, Int'l J. Wildland Fire, 16: 458-462. http://dx.doi.org/10.1071/WF06079.

[27] Manzello, S.L., et al., (2009) Mass and Size Distribution of Firebrands Generated from Burning Korean Pine (Pinus koraiensis) Trees, Fire and Materials 33:21-31, http://dx.doi.org/10.1002/fam.977/.

[28] Suzuki, S., Manzello, S.L., Lage, M., Laing, G., (2012) Firebrand Generation Data Obtained From a Full Scale Structure Burn, International Journal of Wildland Fire 21:961-968, http://dx.doi.org/10.1071/WF11133.

[29] Suzuki, S., Manzello, S.L., Hayashi, Y. (2013) The Size and Mass Distribution of Firebrands Collected from Ignited Building Components Exposed to Wind, Proc. Combust. Inst., 34: 2479-2485. http://dx.doi.org/10.1016/j.proci.2012.06.061.

[30] Waterman, T.E., Takata, A.E., Laboratory Study of Ignition of Host Materials by Firebrands, Project J-6142-OCD Work Unit 2539A, IIT Research Institute, Chicago, IL 1969.

[31] Dowling, V.P., (1994) Ignition of Timber Bridges in Bushfires, Fire Safety Journal 22:145-168, http://dx.doi.org/10.1016/0379-7112(94)90070-1.

[32] Ellis, P.F., The Aerodynamic and Combustion Characteristics of Eucalypt Bank - A Firebrand Study, PhD Dissertation, Australian National University, Canberra, 2000.

[33] Ganteaume, A., et al., (2009) Spot Fires: Fuel Bed Flammability and Capability of Firebrands to Ignite Fuel Beds, International Journal of Wildland Fire 18(8):951-969, http://dx.doi.org/10.1071/WF07111.

[34] Manzello, S.L., Cleary, T.G., Shields, J.R., A. Maranghides, A., W. Mell, W.,Yang, J.C., (2008) Experimental Investigation of Firebrands: Generation and Ignition of Fuel Beds , Fire Safety Journal, 43:226-233. http://dx.doi.org/10.1016/j.firesaf.2006.06.010.

[35] Manzello, S.L., Cleary, T.G., Shields, J.R., Yang, J.C., (2006) Ignition of Mulch and Grasses by Firebrands in Wildland-Urban Interface (WUI) Fires, International Journal of Wildland Fire 15:427-431, http://dx.doi.org/10.1071/WF06031.

[36] Manzello, S.L., Cleary, T.G., Shields, J.R., Yang, J.C., (2006) On the Ignition of Fuel Beds by Firebrands, Fire and Materials, 30:77-87. http://dx.doi.org/10.1002/fam.901.

[37] Manzello, S.L., Shields, J.R., Yang, J.C., Hayashi, Y., Nii, D., On the Use of a Firebrand Generator to Investigate the Ignition of Structures in WUI Fires, In Proceedings of the 11th International Conference on Fire Science and Engineering (INTERLFAM), Interscience Communications, London, 2007, pp. 861-872.

[38] Manzello, S.L., Shields, J.R., Hayashi, Y., Nii, D., (2008) Investigating the Vulnerabilities of Structures to Ignition From a Firebrand Attack, in: B. Karlsson (Ed.) Fire Safety Science- Proceedings of the Ninth International Symposium, IAFSS, 9;143-154, http://dx.doi.org/10.3801/IAFSS.FSS.9-143. 
[39] Manzello, S.L., Hayashi, Y., Yoneki, Y., Yamamoto, Y., (2010) Quantifying the Vulnerabilities of Ceramic Tile Roofing Assemblies to Ignition During a Firebrand Attack, Fire Safety Journal 45:35-43, http://dx.doi.org/10.1016/j.firesaf.2009.09.002.

[40] Manzello, S.L., Park, S.H., Shields, J.R., Suzuki, S., Hayashi., Y., (2011) Determining Structure Vulnerabilities to Firebrand Showers in Wildland-Urban Interface (WUI) Fires, Fire Safety Journal 46:568578, http://dx.doi.org/10.1016/j.firesaf.2011.09.003

[41] Manzello, S.L., Suzuki, S., and Hayashi, Y., (2012) Exposing Siding Treatments, Walls Fitted with Eaves, and Glazing Assemblies to Firebrand Showers. Fire Safety Journal 50:25-34, http://dx.doi.org/10.1016/j.firesaf.2012.01.006.

[42] Manzello, S.L., The Performance of Concrete Tile and Terracotta Tile Roofing Assemblies Exposed to Wind-Driven Firebrand Showers, NIST Technical Note 1794, 2013 http://dx.doi.org/10.6028/NIST.TN.1794.

[43] Manzello, S.L., Suzuki, S., and Hayashi, Y., (2012) Enabling the Study of Structure Vulnerabilities to Ignition from Wind Driven Firebrand Showers: A Summary of Experimental Results, Fire Safety Journal, 54:181-196. http://dx.doi.org/10.1016/j.firesaf.2012.01.006

[44] Manzello, S.L., Suzuki, S., (2013) Experimentally Simulating Wind Driven Firebrand Showers in Wildland-Urban Interface (WUI) Fires: Overview of the NIST Firebrand Generator (NIST Dragon) Technology, Procedia Engineering, 62:91-102. http://dx.doi.org/10.1016/j.proeng.2013.08.047.

[45] http://www.disastersafety.org

[46] Suzuki, S., Manzello, S.L, On the Development and Characterization of a Reduced Scale Continuous Feed Firebrand Generator, Fire Safety Science - Proceedings of the $10^{\text {th }}$ International Symposium 10:1437-1448, 2011. http://dx.doi.org/10.3801/IAFSS,10-1437.

[47] Manzello, S.L., and Suzuki, S., (2012) The New and Improved Dragon's LAIR (Lofting and Ignition Research) Facility, Fire and Materials 36:623-635, http://dx.doi.org/10.1002/fam.1123.

[48] Manzello, S.L, Suzuki, S., (2014) Exposing Wood Decking Assemblies to Continuous Wind-Driven Firebrand Showers, Fire Safety Science - Proceedings of the $11^{\text {th }}$ International Symposium in press.

[49] Manzello, S.L., Suzuki, S., Suzuki, J.,Hayashi, Y. Firebrands Generated from Full-Scale Building Components and Structures Under and Applied Wind Field, In Proceedings of the 13th International Conference on Fire Science and Engineering (INTERLFAM), Interscience Communications, London, 2013, pp. 1419-1430.

[50] Manzello, S.L., Himoto, K., (2012) Large Outdoor Fires Special Issue (Guest Editors), Fire Safety Journal 54: 143-217 http://dx.doi.org/10.1016/j.firesaf.2012.07.001

[51] Manzello, S.L., et al., (2013) Workshop for Fire Structure Interaction and Urban and Wildland-Urban Interface (WUI) Fires - Operation Tomodachi Fire Research, Fire Safety Journal, 59:122-131. http://dx.doi.org/10.1016/j.firesaf.2013.03.021

[52] Pellegrino, J., Bryner, N.P., and Johnsson, E.L., Wildland-Urban Interface (WUI) Fire Research Needs - Workshop Summary Report, NIST SP 1150, 2013 http://dx.doi.org/10.6028/NIST.SP.1150.

[53] Maranghides A., Mell. W, Framework for Addressing the National Wildland Urban Interface Fire Problem-Determining Fire and Ember Exposure Zones using a WUI Hazard Scale , NIST Technical Note $1748,2012$. 